\title{
PHYSICAL EDUCATION ROLE IN LITHUANIAN PRIMARY SCHOOLCHILDREN PHYSICAL LITERACY FORMATION
}

\author{
Monika Širkaitè, Rita Gruodytè-Račienè \\ Lithuanian Sport University, Lithuania
}

\begin{abstract}
Lifelong engagement in physical activity (PA) may be increased and secured by achieving a sufficient level of physical literacy (PL) during childhood. The aim of this study is to assess if the level of physical activity (PL Domain 1), fitness (PL Domain 2), motivation and confidence (PL Domain 3), knowledge and understanding (PL Domain 4) of primary schoolchildren is sufficient. In addition, to investigate whether physical literacy of the $3^{\text {rd }}$ grade students differ in relation to Physical Education (PE) being taught by their respective General teacher. For this purpose 9-10 year old students of four different classes of the same cohort $(n=93)$ of one of the school in second biggest city of Lithuania were recruited. The findings of this cross-sectional pilot study indicates that PA and physical competence for most of participants were of average or higher level, however, majority of them have not yet reached an acceptable level in such PL domains as Motivation \& Confidence and Knowledge \& Understanding. Significant differences $(p<0.05)$ comparing by class were found in Knowledge \& Understanding, and in physical fitness domains. We may conclude that lower motivation, confidence and knowledge in PE determines lower physical literacy of primary schoolchildren. Furthermore, differences revealed in such PL domains as knowledge and understanding as well as physical fitness with regard to the different class and their respective general teacher may indicate the importance of the educator's role and implemented PE curriculum for attaining the sufficient level of physical literacy of primary schoolchildren.
\end{abstract}

Keywords: children, healthy lifestyle behaviour, physical activity, physical education, physical literacy.

\section{Introduction}

Physical literacy (PL) is a concept that has been growing very fast and recently gained a momentum in many different countries (Spengler, Cohen, 2015). It has been proposed as a foundation for the development of skills, knowledge, and attitudes that are essential for lifelong participation in physically active lifestyle (Whitehead, 2013). Supporting physical literacy 
in the growing years is crucially important considering the rising levels of physical inactivity (Reilly et al., 2004) and the prevalence of obesity (Ogden et al., 2016) among children. The main goal of PL to increase lifelong engagement in physically active behaviors is very appealing knowing how critical the movement and exercising is for children's health and well-being (Poitras et al., 2016).

Physically literate persons should be motivated and confident to take part in various forms of physical activity, have physical competence, knowledge, and understanding of the importance of maintaining physical activity throughout the lifetime (Whitehead, 2013). Research showed that physical activity helps to increase some health benefits such as reducing the risk of cardiovascular disease, diabetes, and cancer (Warburton et al., 2006). Accordingly, the promotion of physical literacy could help to increase physical activity in children which could help to develop some health benefits (Gately, 2010) and even increase academic performance (Guo et al., 2012). The fundaments about the importance of physical activity to lifelong health and well-being should be developed during school years (Whitehead, 2013). That is why education is very essential for physical literacy development (Hyndman, Pill, 2018). This makes it particularly important to clarify the meaning of physical literacy, ways of developing it and the likely consequences of promoting it.

In primary school, the main competences and attitudes are achieved and formed: a child who has mastered the fundamental movement skills has a higher chance of becoming physically literate and having a long lasting interest in a physically active lifestyle (Whitehead, 2013). As they progress during this stage there should be an increase in discussions towards the importance and the benefits of physical activity for the body. A lot of responsibilities during this stage of physical literacy development fall onto Physical Education (PE) teacher's shoulders, however parents, family and peers play an important role as well (Whitehead, 2013). Physical Education helps to develop physical competences making children move effectively, efficiently, and safely (Roetert, Jefferies, 2014). However, the main outcome of PE should be the focus on physical literacy - an essential basis for overall child development - and not merely on physical competencies. A complex of variables such as physical competence, daily behavior, motivation and confidence, knowledge and understanding constitute physical literacy which should serve as a goal for PE in helping to build a strong foundation for a child to participate in physical activity and stay healthy over the lifespan (Sum et al., 2016). Since physical activity behaviors are being established in early years (Edwards et al., 2018), the lifelong engagement in PA may be increased and secured by achieving a sufficient level of physical literacy in childhood. 
The aim of this study was to assess if the level of physical activity (PL Domain 1), health-related physical fitness (PL Domain 2), motivation and confidence (PL Domain 3), knowledge and understanding (PL Domain 4) of primary schoolchildren is sufficient. In addition, to investigate whether physical literacy of the 3rd grade students differ in relation to PE being taught by their respective general teacher.

\section{Methodology}

In total, ninety three 9-10 year old students of four different classes of the same $3^{\text {rd }}$ grade cohort of one of the school in second biggest city of Lithuania were recruited: Class A $(n=24)$, Class B $(n=24)$, Class C $(n=23)$, and Class $\mathrm{D}(n=22)$. They had two weekly PE lessons regularly, taught by their respective General teachers, sharing the same sport facilities and equipment. According to Canadian Association of Physical Literacy (CAPL) Manual (Healthy Active Living and Obesity Research Group, 2013). Canadian Assessment for Physical Literacy: Manual for test administration. Ottawa: Children's Hospital of Eastern Ontario Research Institute., the four domains of schoolchildren physical literacy are to be estimated: (1) Daily Behaviour Domain, (2) Physical Competence Domain, (3) Knowledge \& Understanding Domain, and (4) Motivation \& Confidence Domain (Healthy Active Living \& Obesity Research Group, 2013). Few modifications were applied to the original CAPL Protocol due to inability to follow it precisely (details provided in subsequent chapters). All measurements and surveys were conducted by the same Principal Investigator and completed in November 2019.

\section{Daily Behaviour Domain}

For Daily Behaviour Domain investigation, the data on an average daily steps, self-reported sedentary time, and self-reported number of days a week a child engages in moderate to vigorous PA (MVPA) is to be examined, constituting 32 points of the total 100 points of PL score (Longmuir et al., 2015). In this study, the Netherland Physical Activity Questionnaire (NPAQ) was used to assess what activities children prefer to do in their free time (Janz et al., 2005). The questionnaire is to be filled by a parent or legal guardian. It includes seven statements that help to evaluate children leisure time preferences and every day activity choices rather than intensity, duration or frequency of PA (PL Domain 1). The NPAQ score may range from 7 (low physical activity) to 35 (high physical activity). 


\section{Physical Competence Domain}

According to CAPL (Longmuir et al., 2015), the Physical Competence Domain is evaluated by following tests and measurements: PACER shuttle run, overall obstacle course, grip strength, plank, Body Mass Index (BMI) percentile, waist circumference, and sit \& reach (the results of which constitute another 32 points of PL score). However, for this study Physical Fitness Test Battery for Children (Fjørtoft et al., 2011) was used to evaluate health-related physical fitness (PL Domain 2). The methodology is easy to apply because the tests do not require additional hardware and are easy to administer. It helps to measure not the separate elements but the overall physical competence of children which gives a holistic view of the problem. The tests measured explosive power, arms and leg muscle power, cardiovascular endurance capacity and coordination of children. Every participant had to perform five tests related to their daily motor activities such as jumping, running and throwing, i. e. standing broad jump, jumping $7 \mathrm{~m}$ distance on one and two legs, $1 \mathrm{~kg}$ medicine ball push and $6 \mathrm{~min}$ endurance run. To exam whether physical competence results of boys and girls met minimal, average or maximal level, the Reference scales of Lithuanian schoolchildren (Česnaitienè et al., 2016) were advised. In addition, body height $(\mathrm{cm})$ and body mass $(\mathrm{kg})$ were assessed to calculate BMI $\left(\mathrm{kg} / \mathrm{m}^{2}\right)$. Children were dressed in light clothing and wearing no shoes. Height was measured to the nearest $0.1 \mathrm{~cm}$ using a Stadiometer (SECA 213) in a standing position with shoulders relaxed, facing forward with head and back facing the wall while body mass was measured to the nearest $0.05 \mathrm{~kg}$ using a regular weight measuring scales.

\section{Motivation and Confidence Domain}

The Motivation and Confidence domain was assessed using the Children's Self-Perception of Adequacy in and Predilection for Physical Activity (CSAPPA) Scale (Healthy Active Living \& Obesity Research group, 2013). It was used to measure children's perception of their abilities to perform physical activities successfully and their predilection towards participation in physical activities. Also, questions asking about the "reasons to be physically active" and "reasons not to be physically active" were combined to create a perceived benefit to barrier ratio towards physical activity. Question No. 4 was related to their activity levels compared to peers and question No. 5 assessed children's skills level compared to peers. The whole Motivation and Confidence domain score (range -1.5 to 18 points) was comprised from CSAPPA adequacy score (range 1.5 to 6 points), CSAPPA predilection score (range 1.5 to 6 points), benefits to barrier ratio (range -4.7 to 4 points), question No. 4 (range 0.1 to 1 points) and No. 5 (range 0.1 to 1 points). Validity for this CAPL assessment protocol was established 
through the Delphi process (Francis et al., 2016). The score from the Motivation and Confidence domain (PL Domain 3) was calculated (max. 18 points of the total 100 points of PL score) and assigned to one of the four categories: Beginning, Progressing, Achieving and Excelling (Francis et al., 2016).

\section{Knowledge and Understanding Domain}

To measure what knowledge and understanding children have in physical and health education (PL Domain 4) a self-reported questionnaire with 14 questions was used (the CAPL manual for test administration established by the Healthy Active Living and Obesity Research group, 2013). For example, children were asked to indicate the maximum amount of screen time that is recommended for their age group and to select the correct definition for terms within the health curriculum (e. g. cardiorespiratory fitness, muscular strength or endurance). Also, their perceptions towards health and the usage of safety gear during different activities. Validity for this CAPL assessment protocol was established through the Delphi process (Francis et al., 2016). The score from the Knowledge and Understanding domain was calculated (collecting another max. 18 points of the total 100 points of PL score) and assigned to one of the four categories: Beginning, Progressing, Achieving and Excelling (Francis et al., 2016).

\section{Statistical analysis}

The conducted information was processed using mathematical-statistical methods. These analyses were undertaken with SPSS 22.0 version. Descriptive statistics including mean and standard deviation $( \pm S D)$ were used. Normality of parameters was controlled by one-sample KolmogorovSmirnov test $(p>0.05)$. Data normality distribution was determined using skewness and kurtosis. The assumption of homogeneity of variances was tested through Levene's test and has been met. The variances were equal. To compare variables by physical literacy stages (Beginning, Progressing, Achieving, Excelling), gender and class (General Teacher) the one-way ANOVA was used and Tukey post hoc tests were used to indicate which groups are different from each other. The significance level was set at $p<0.05$.

\section{Results}

The anthropometric and physical activity characteristics of primary school children are presented in Table 1 . The significant difference between boys and girls was obtained in their body height, i. e. boys were taller compared to girls (141.3 \pm 7.3 vs. $137.4 \pm 6.4 \mathrm{~cm}$, respectively; $p<0.05$ ). 
According to the World Health Organization (WHO) recommendations (2007) for children aged 5 to 19 years old, the BMI $\left(\mathrm{kg} / \mathrm{m}^{2}\right)$ results of the participants (PL Domain 2) were of normal level (18.8 \pm 4.7 and $17.9 \pm$ 3.1 of boys and girls, respectively). The mean score of leisure time physical activity (PL Domain 1) of primary school children was $25.6 \pm 4.7$ points (of max. 35), and no significant differences by gender were found. (Table 1).

Table 1. Participants' anthropometric characteristics and physical activity data (presented as mean $\pm \mathrm{SD}$ )

\begin{tabular}{|l|l|l|l|}
\hline \multicolumn{2}{|l|}{$\begin{array}{l}\text { Boys } \\
(\boldsymbol{n}=59)\end{array}$} & $\begin{array}{l}\text { Girls } \\
(\boldsymbol{n}=33)\end{array}$ & $\begin{array}{l}\text { Total } \\
(\boldsymbol{n}=92)\end{array}$ \\
\hline Anthropometric characteristics \\
\hline Height $(\mathrm{cm})$ & $141.3 \pm 7.3$ & $137.4 \pm 6.4^{*}$ & $139.9 \pm 7.2$ \\
\hline Weight $(\mathrm{kg})$ & $38.1 \pm 12.2$ & $33.9 \pm 7.6$ & $36.6 \pm 10.8$ \\
\hline BMI $\left(\mathrm{kg} / \mathrm{m}^{2}\right)$ & $18.8 \pm 4.7$ & $17.9 \pm 3.1$ & $18.5 \pm 4.2$ \\
\hline Physical activity & $(n=53)$ & $(n=32)$ & $(n=85)$ \\
\hline \multicolumn{5}{|l|}{} \\
\hline NPAQ score (points) & $26.3 \pm 4.6$ & $24.6 \pm 4.8$ & $25.6 \pm 4.7$ \\
\hline
\end{tabular}

NOTE: BMI - body mass index; NPAQ - the Netherland Physical Activity Questionnaire

The findings of physical competence for most of primary schoolchildren were of average or higher level according to the Lithuanian primary schoolchildren reference scale (Table 2). In leg muscle power, arm muscle strength and cardiovascular endurance the results were of average level, and in explosive power it was meeting a minimum level of physical fitness, only.

Table 2. Primary schoolchildren health-related physical fitness (PL Domain 2): levels according to Lithuanian primary schoolchildren reference scales

\begin{tabular}{|l|l|l|l|}
\hline $\begin{array}{l}\text { Physical fitness } \\
\text { component }\end{array}$ & Test & $\begin{array}{l}\text { Total } \\
(\boldsymbol{n}=\mathbf{8 6})\end{array}$ & $\begin{array}{l}\text { Physical } \\
\text { fitness level }\end{array}$ \\
\hline Explosive power & Broad jump (cm) & $126.2 \pm 21.6$ & Minimum \\
\hline $\begin{array}{l}\text { Leg muscle power, } \\
\text { coordination }\end{array}$ & $\begin{array}{l}\text { Jumping 7m distance } \\
\text { on one leg (s) }\end{array}$ & $3.2 \pm 0.7$ & Average \\
\cline { 2 - 3 } & $\begin{array}{l}\text { Jumping 7m distance } \\
\text { on two legs (s) }\end{array}$ & $3.4 \pm 0.6$ & \\
\hline Arms muscle strength & Medicine ball push (m) & $4.6 \pm 1.1$ & Average \\
\hline Cardiovascular endurance & 6 min run (m) & $881.2 \pm 153.7$ & Average \\
\hline
\end{tabular}


The results from the Canadian Assessment of Physical Literacy Motivation and Confidence score indicate that participants were only at the beginning and progressing stage (28.9\% and $71.1 \%$, respectively). Similarly, the majority of the respondents have not yet reached an acceptable level of physical literacy in Knowledge \& Understanding domain: 6.6\% and 53.8\% of participants were only at beginning and progressing stage, respectively; although $29.7 \%$ have reached an adequate level, and 9.9\% even the highest level of physical literacy (see Table 3).

Table 3. The evaluation of primary schoolchildren $(n=91)$ Motivation \& Confidence and Knowledge \& Understanding domains: distribution by scores assigned to a respective interpretation category by Canadian Assessment of Physical Literacy (CAPL) protocol (Francis et al., 2016)

\begin{tabular}{|c|c|c|c|c|}
\hline $\begin{array}{l}\text { PL category } \\
\text { CAPL domain }\end{array}$ & \begin{tabular}{|l} 
Beginning \\
$(n, \%)$
\end{tabular} & \begin{tabular}{|l|} 
Progressing \\
$(n, \%)$
\end{tabular} & $\begin{array}{l}\text { Achieving } \\
(n, \%)\end{array}$ & $\begin{array}{l}\text { Excelling } \\
(n, \%)\end{array}$ \\
\hline $\begin{array}{l}\text { Motivation and Confidence } \\
\text { (PL Domain } 3 \text { ) }\end{array}$ & $27(29.7 \%)$ & $64(70.3 \%)$ & - & - \\
\hline $\begin{array}{l}\text { Knowledge and } \\
\text { Understanding } \\
\text { (PL Domain 4) }\end{array}$ & $6(6.6 \%)$ & $49(53.8 \%)$ & 27 (29.7 \%) & $9(9.9 \%)$ \\
\hline
\end{tabular}

Note: PL - physical literacy; CAPL - the Canadian Assessment of Physical Literacy

Comparing the physical literacy of primary schoolchildren results in four different domains by a class (their respective General Teacher), the significant differences ( $p<0.05$ ) were found in two of the PL Domains, i. e. Physical Competence (PL Domain 2) and Knowledge \& Understanding (PL Domain 4) (Table 4). The measurements of the overall physical competence of children revealed several significant differences and problematic issues among the four classes, particularly in leg muscle strength and cardiorespiratory endurance (lowest results in class B) and arm muscle strength (lowest results in class D). The score in knowledge and understanding of boys and girls in class A was the highest of all groups, and significantly differed compared to their counterparts in classes B and C (11.68 \pm 2.06 vs. $9.57 \pm 2.64$ and $9.71 \pm 1.95$ points, respectively). Other PL Domains such as daily behaviour (physical activity) and motivation and confidence were not signifficantly different with respect to the class (General Teacher). 
Table 4. Physical literacy of primary schoolchildren comparing by Class/ General teacher (mean \pm SD)

\begin{tabular}{|c|c|c|c|c|}
\hline PL domain & \begin{tabular}{|l} 
Class A \\
$(n=24)$
\end{tabular} & \begin{tabular}{|l} 
Class B \\
$(n=24)$ \\
\end{tabular} & $\begin{array}{l}\text { Class } \\
(n=23)\end{array}$ & $\begin{array}{l}\text { Class D } \\
(n=22)\end{array}$ \\
\hline \multicolumn{5}{|l|}{ Daily Behaviour } \\
\hline $\begin{array}{l}\text { Physical } \\
\text { activity level } \\
\text { (NPAQ score/ } \\
\text { points) }\end{array}$ & $25.32 \pm 4.16$ & $26.05 \pm 4.45$ & $25.9 \pm 4.61$ & $25.25 \pm 5.78$ \\
\hline \multicolumn{5}{|c|}{ Physical Competence } \\
\hline $\begin{array}{l}\text { Broad jump } \\
\text { (cm) }\end{array}$ & $\begin{array}{l}128.87 \pm \\
20.79\end{array}$ & \begin{tabular}{|l}
$124.58 \pm$ \\
26.99
\end{tabular} & $\begin{array}{l}128.21 \pm \\
19.87\end{array}$ & \begin{tabular}{|l|}
$123.30 \pm$ \\
17.48 \\
\end{tabular} \\
\hline $\begin{array}{l}\text { Jumping } 7 \mathrm{~m} \\
\text { distance on one } \\
\text { leg (s) }\end{array}$ & $3.03 \pm 0.35$ & $3.50 \pm 1.09$ & $3.08 \pm 0.49$ & $2.95 \pm 0.69$ \\
\hline $\begin{array}{l}\text { Jumping } 7 \mathrm{~m} \\
\text { distance on two } \\
\text { legs (s) }\end{array}$ & $3.45 \pm 0.35$ & $3.72 \pm 0.61$ & $3.06 \pm 0.49^{b}$ & $3.38 \pm 0.54$ \\
\hline $\begin{array}{l}\text { Medicine ball } \\
\text { push (m) }\end{array}$ & $4.89 \pm 1.24$ & $4.82 \pm 0.95$ & $4.96 \pm 1.09$ & $3.83 \pm 0.98^{a, b}$ \\
\hline $\begin{array}{l}6 \text { min endur- } \\
\text { ance run }(\mathrm{m})\end{array}$ & \begin{tabular}{|l}
$926.44 \pm$ \\
143.03
\end{tabular} & $\begin{array}{l}\text { 765.66 } \pm \\
157.02^{\mathrm{a}}\end{array}$ & $\begin{array}{l}899.2 \pm \\
1^{117.1^{b}}\end{array}$ & $\begin{array}{l}935.83 \pm \\
136.01^{\mathrm{b}} \\
\end{array}$ \\
\hline \multicolumn{5}{|c|}{ Motivation \& Confidence } \\
\hline $\begin{array}{l}\text { CAPL score } \\
\text { (points) }\end{array}$ & $9.35 \pm 1.62$ & $9.58 \pm 1.99$ & $9.28 \pm 1.02$ & $9.41 \pm 1.57$ \\
\hline \multicolumn{5}{|c|}{ Knowledge \& Understanding } \\
\hline $\begin{array}{l}\text { CAPL score } \\
\text { (points) }\end{array}$ & $11.68 \pm 2.06$ & $9.57 \pm 2.64^{\mathrm{a}}$ & $9.71 \pm 1.95^{\mathrm{a}}$ & $10.06 \pm 2.89$ \\
\hline
\end{tabular}

Note: PL - physical literacy; NPAQ - the Netherland Physical Activity Questionnaire; CAPL - the Canadian Assessment of Physical Literacy; ${ }^{a}$ - significant difference from Class $A ;{ }^{b}$ - significant difference from Class $B ;{ }^{c}-$ significant difference from Class $C$; in Bold - level of significance $p<0.01$

\section{Discussion}

Our research aimed to assess if the physical literacy level of primary school children is sufficient using such components as physical activity ( $P L$ Domain 1), fitness ( $P L$ Domain 2), motivation and confidence (PL Domain 3), knowledge and understanding (PL Domain 4). The levels of these elements and the relationships between these variables in primary schoolchildren were analyzed to test the hypothesis that the physical literacy of primary school children is of average level and that it differs 
in relation to PE being taught by their respective general teacher. The findings of this cross-sectional pilot study indicate that PA and physical competence for most of primary schoolchildren were of average or higher level according to the Lithuanian primary schoolchildren reference scale. Also, a significant difference were noticed in physical fitness domain, particularly in leg and arm muscle strength and cardiorespiratory endurance with regard to a class (general teacher). Our hypothesis was confirmed since children's physical literacy level appeared to be of average level and there was a significant difference in knowledge and understanding as well as physical fitness with regard to the different class and their respective general teacher.

Being physically literate means to value and take responsibility in physically active lifestyle choices. Physical activity behaviors are being established in early years of life (Edwards et al., 2018). As parents note, few of the most affecting factors that would help to increase physical activity of their children is better conditions for exercise in schools (80.1\%), more active people that surrounds them (75.2\%) and stronger education towards physical activity importance and benefits for health (70.1\%) (Strukčinskienė, Raistenskis, 2012). In our study the physical activity analysis using the NPAQ instrument indicated no significant differences in primary schoolchildren neither by gender nor by class with a quite high mean score of $25.6 \pm 4.7$ points (the range is of 7 to 35 ). The research conducted in Brazil, which measured children's physical activity using the same questionnaire, revealed that the recommended amount of daily health-enhancing physical activity - $60 \mathrm{~min} /$ day of moderate to vigorous physical activity (MVPA) - was achieved by the majority (73.2\%) of the participants (Bielemann, Reichert, 2011). In contrast, only $18.6 \%$ of boys and $9.8 \%$ of girls living in urban areas were meeting the WHO recommendations based on the results of a previous study aiming to evaluate Lithuanian school children physical activity level (Volbekiené et al., 2007).

In this research, participants performed five different health-related physical fitness tests such as standing broad jump, jumping $7 \mathrm{~m}$ distance on one and two legs, $1 \mathrm{~kg}$ medicine ball push and 6 min endurance run to assess their explosive power, arms and leg muscle power, cardiovascular endurance capacity and coordination. The results were compared to the reference scales of Lithuanian primary schoolchildren (Česnaitienè et al., 2016) and were of average level mainly. During the past two decades the change in physical fitness of school-aged children in Lithuania has demonstrated negative trends, especially in aerobic capacity (cardiorespiratory fitness) which declined about 50\% (Venckunas et al., 2017). Accordingly, the muscular strength and endurance, flexibility, and especially cardiovascular 
endurance of children are significantly associated with their total weekly physical activity minutes (Chen et al., 2018).

The findings of physical literacy in Motivation \& Confidence and Knowledge \& Understanding scores indicate that participants were only at the beginning and progressing stage (28.9\% and $71.1 \%$; $6.6 \%$ and $53.8 \%$, respectively). Knowing that individual's motivation for and confidence in exercising usually declines the most during adolescence (Eather, Morgan, 2013), it is concerning, considering that the levels of motivation and confidence are already low at primary school age. As mentioned before, education is very important for this age group (Whitehead, 2013; Hyndman, Pill, 2018). A study revealed that children who were instructed by professional physical education teachers were more motivated and confident, and were even meeting achieving and excelling stages in physical literacy (Law et al., 2018). Another research found that when children have the power of choice, they experience autonomy, which increases their intrinsic motivation to participate in physical activities they enjoy now and in the future (Roemmich et al., 2012). It was very effective among girls and showed that when girls were able to choose their activity, they were motivated to participate in physical activities equal to boys (Roemmich et al., 2012).

One limitation of this study was that levels of physical activity were measured using self-reported questionnaires despite the fact it being validated and used in other studies. Also, other modifications were applied to physical competence domain, e. g. different musculoskeletal fitness tests were performed and the overall obstacle course as well as Progressive Aerobic Cardiovascular Endurance Run (PACER) were not measured. Some modifications were applied for motivation and confidence as well as knowledge and understanding questionnaire to adjust to Lithuanian children exercise habits and climate differences, e. g. different activities were chosen in the $11^{\text {th }}$ question (i. e. instead of snowmobiling it was changed to snowboarding). Due to that it was not possible to replicate the original version of the Canadian Assessment of Physical Literacy model. Nevertheless, the strength of this study might be supported by the fact that in Lithuania the phenomena of physical literacy is not yet well investigated. For future perspectives, it is necessary to search for solution to validate the CAPL assessment tools for Lithuanian population investigating physical literacy.

\section{Conclusions}

We may conlude that lower motivation, confidence and knowledge in PE determines lower physical literacy of primary schoolchildren. Furthermore, the differences revealed in such PL domains as knowledge 
and understanding as well as physical fitness with regard to the different class and their respective General teacher may indicate the importance of the educator's role and implemented PE curriculum for attaining the sufficient level of physical literacy of 9-10 year old boys and girls.

\section{Reference}

Bielemann, R. M., Reichert, F. F., Paniz, V. M., \& Gigante, D. P. (2011). Validation of the Netherlands physical activity questionnaire in Brazilian children. International Journal of Behavioral Nutrition and Physical Activity, 8(1), 1-8.

Česnaitienè, V. J., Emeljanovas, A. ir Miežienè, B. (2016). Ikimokyklinio ir pradinio mokyklinio amžiaus vaikų fizinio pajègumo vertinimo metodika: metodinè medžiaga. Kaunas: Lietuvos Sporto Universitetas. [Methodology for assessing the physical capacity of preschool and primary school children. Kaunas: Lithuanian Sports University].

Chen, W., Hammond-Bennett, A., Hypnar, A., \& Mason, S. (2018). Health-related physical fitness and physical activity in elementary school students. BMC Public Health, 18(1), 1-12.

Eather, N., Morgan, P. J., \& Lubans, D. R. (2013). Social support from teachers mediates physical activity behavior change in children participating in the Fit-4-Fun intervention. International Journal of Behavioral Nutrition and Physical Activity, 10(1), 1-15.

Edwards, L. C., Bryant, A. S., Keegan, R. J., Morgan, K., Cooper, S. M., \& Jones, A. M. (2018). 'Measuring' Physical Literacy and Related Constructs: A Systematic Review of Empirical Findings. Sports medicine (Auckland, N. Z.), 48(3), 659-682. doi:10.1007/ s40279-017-0817-9

Fjørtoft, I., Pedersen, A. V., Sigmundsson, H., \& Vereijken, B. (2011). Measuring physical fitness in children who are 5 to 12 years old with a test battery that is functional and easy to administer. Physical therapy, 91(7), 1087-1095.

Francis, C. E., Longmuir, p. E., Boyer, C., Andersen, L. B., Barnes, J. D., Boiarskaia, E., ... \& Hay, J. A. (2016). The Canadian Assessment of Physical Literacy: development of a model of children's capacity for a healthy, active lifestyle through a Delphi process. Journal of Physical Activity and Health, 13(2), 214-222.

Gately, P. (2010). Physical literacy and obesity. Physical Literacy, Routledge, 83-99.

Guo, Y., Justice, L. M., Kaderavek, J. N., \& McGinty, A. (2012). The literacy environment of preschool classrooms: Contributions to children's emergent literacy growth. Journal of research in reading, 35(3), 308-327.

Healthy Active Living and Obesity Research Group (2013). Canadian Assessment for Physical Literacy: Manual for test administration. Ottawa: Children's Hospital of Eastern Ontario Research Institute.

Hyndman, B., \& Pill, S. (2018). What's in a concept? A Leximancer text mining analysis of physical literacy across the international literature. European Physical Education Review, 24(3), 292-313.

Janz, K. F., Broffitt, B., \& Levy, S. M. (2005). Validation evidence for the Netherlands physical activity questionnaire for young children: the Iowa bone development study. Research quarterly for exercise and sport, 76(3), 363-369. 
Law, B., Bruner, B., Benson, S. M. S., Anderson, K., Gregg, M., Hall, N., ... \& Tremblay, M. S. (2018). Associations between teacher training and measures of physical literacy among Canadian 8-to 12-year-old students. BMC Public Health, 18(2), 1-11.

Longmuir, P. E., Boyer, C., Lloyd, M., Yang, Y., Boiarskaia, E., Zhu, W., \& Tremblay, M. S. (2015). The Canadian assessment of physical literacy: methods for children in grades 4 to 6 (8 to 12 years). BMC public health, 15(1), 1-11.

Ogden, C. L., Carroll, M. D., Lawman, H. G., Fryar, C. D., Kruszon-Moran, D., Kit, B. K., \& Flegal, K. M. (2016). Trends in obesity prevalence among children and adolescents in the United States, 1988-1994 through 2013-2014. Jama, 315(21), 2292-2299.

Poitras, V. J., Gray, C. E., Borghese, M. M., Carson, V., Chaput, J. P., Janssen, I., ... \& Sampson, M. (2016). Systematic review of the relationships between objectively measured physical activity and health indicators in school-aged children and youth. Applied Physiology, Nutrition, and Metabolism, 41(6), S197-S239.

Reilly, J. J., Jackson, D. M., Montgomery, C., Kelly, L. A., Slater, C., Grant, S., \& Paton, J. Y. (2004). Total energy expenditure and physical activity in young Scottish children: mixed longitudinal study. The Lancet, 363(9404), 211-212.

Roemmich, J. N., Lambiase, M. J., McCarthy, T. F., Feda, D. M., \& Kozlowski, K. F. (2012). Autonomy supportive environments and mastery as basic factors to motivate physical activity in children: a controlled laboratory study. International Journal of Behavioral Nutrition and Physical Activity, 9(1), 1-13.

Roetert, E. P., \& Jefferies, S. C. (2014). Embracing physical literacy. Journal of Physical Education, Recreation and Dance, 85(8), 38-40.

Spengler, J. O., \& Cohen, J. (2015). Physical literacy: A global environ-mental scan. Washington, DC: Aspen Institute Sports \& Society Program. Retrieved from: https:// www.shapeamerica.org/uploads/pdfs/GlobalScan_FINAL.pdf

Strukčinskienė, B., \& Raistenskis, J. (2012). Lietuvos pradinių klasių mokinių fizinio aktyvumo ypatumai. Visuomenès sveikata, 1(1), 35-51.

Sum, R. K. W., Ha, A. S. C., Cheng, C. F., Chung, p. K., Yiu, K. T. C., Kuo, C. C. (2016). Construction and Validation of a Perceived Physical Literacy Instrument for Physical Education Teachers. PLoS ONE, 11(5), 1-10. https://doi.org/10.1371/journal. pone. 0155610 .

Venckunas, T., Emeljanovas, A., Mieziene, B., \& Volbekiene, V. (2017). Secular trends in physical fitness and body size in Lithuanian children and adolescents between 1992 and 2012. J Epidemiol Community Health, 71(2), 181-187.

Volbekienè, V., Griciūtè, A., Gaižauskienè, A. (2007). Lietuvos didžiujų miestų 5-11 klasių moksleivių su sveikata susijęs fizinis aktyvumas. Ugdymas Kūno kultūra. Sportas, 2, 71-77.

Warburton, D. E., Nicol, C. W., \& Bredin, S. S. (2006). Health benefits of physical activity: the evidence. CMAJ: Canadian Medical Association journal=journal de l'Association medicale canadienne, 174(6), 801-809. doi:10.1503/cmaj.051351

Whitehead, M. (2013). Definition of physical literacy and clarification of related issues. ICSSPE Bulletin, 65(1.2), 29-34.

World Health Organization (2007). BMI-for-age (5-19 years). Retrieved from: https:// www.who.int/tools/growth-reference-data-for-5to19-years/indicators/bmi-for-age 